problems that someone will have to be responsible for solving. Programs that are established directly between libraries rather than between universities may have fewer complications. The Staff Development Committee is now writing guidelines for the library so that in the future an exchange might run more effectively.

There has to be some consideration on the part of the administration of what is gained in knowledge and experience in such a leave. There are some questions as to whether this is a true "research leave." It certainly was an activity which broadened the scope and breadth of knowledge for both of these professional librarians. Whether or not they will actually put to use skills or techniques learned during their visits is a moot question. In my opinion, it is significant that they both experienced a totally different environment from the one for which they had been trained. How many administrators have wished their staff had worked in more than one position in one location during their careers? Since they are both extremely intelligent young librarians, I hope that the exchanges will be one step in furthering their career development. Both have taken courageous steps into unknown environments, and have returned to their own home institutions revitalized and enthused over what they had learned. This alone may have been more than worth all the other costs.

\title{
Springtime in Germany
}

\author{
By Gretchen Yealy \\ Serials Cataloger \\ Brown University
}

\section{Another perspective-Brown goes to Bamberg.}

D uring the spring of 1986 I spent three months as an exchange librarian at the Universitätsbibliothek Bamberg in West Germany. I worked in each of the major library departments, with special emphasis on cataloging, my area of concentration at home at Brown University. While three months is hardly long enough to learn everything there is to know about a complex university library, I had a chance to observe routines both similar to and very different from those at home. In addition, I grappled with a number of cultural conflicts, both linguistic and professional in nature.

The Universität Bamberg is a relatively young German university. It was organized in the 1970s on the sites of earlier schools of pedagogy and theology in the northern Bavarian city of Bamberg. As is usual in Germany, there is no "campus." The uni- versity and its libraries are spread out among many old and new buildings in a lovely city of about 80,000 people. Bamberg escaped major damage during both world wars and attracts many tourists who crowd its picturesque market area and numerous churches. I wore out several pairs of shoes on the scenic cobblestone streets, and rejoiced with the tourists when the chilly, damp weather endemic to the area in early spring eventually gave way to the sunshine and warmth of May and June.

Dealing with a foreign language every day at work and on the streets was by far the most challenging aspect of the exchange for me. Regina Krepulat, my exchange partner, had spent six months at Brown during the fall of 1985 , and I had constantly been impressed by her skill and aplomb in speaking English. While my comprehension im- 


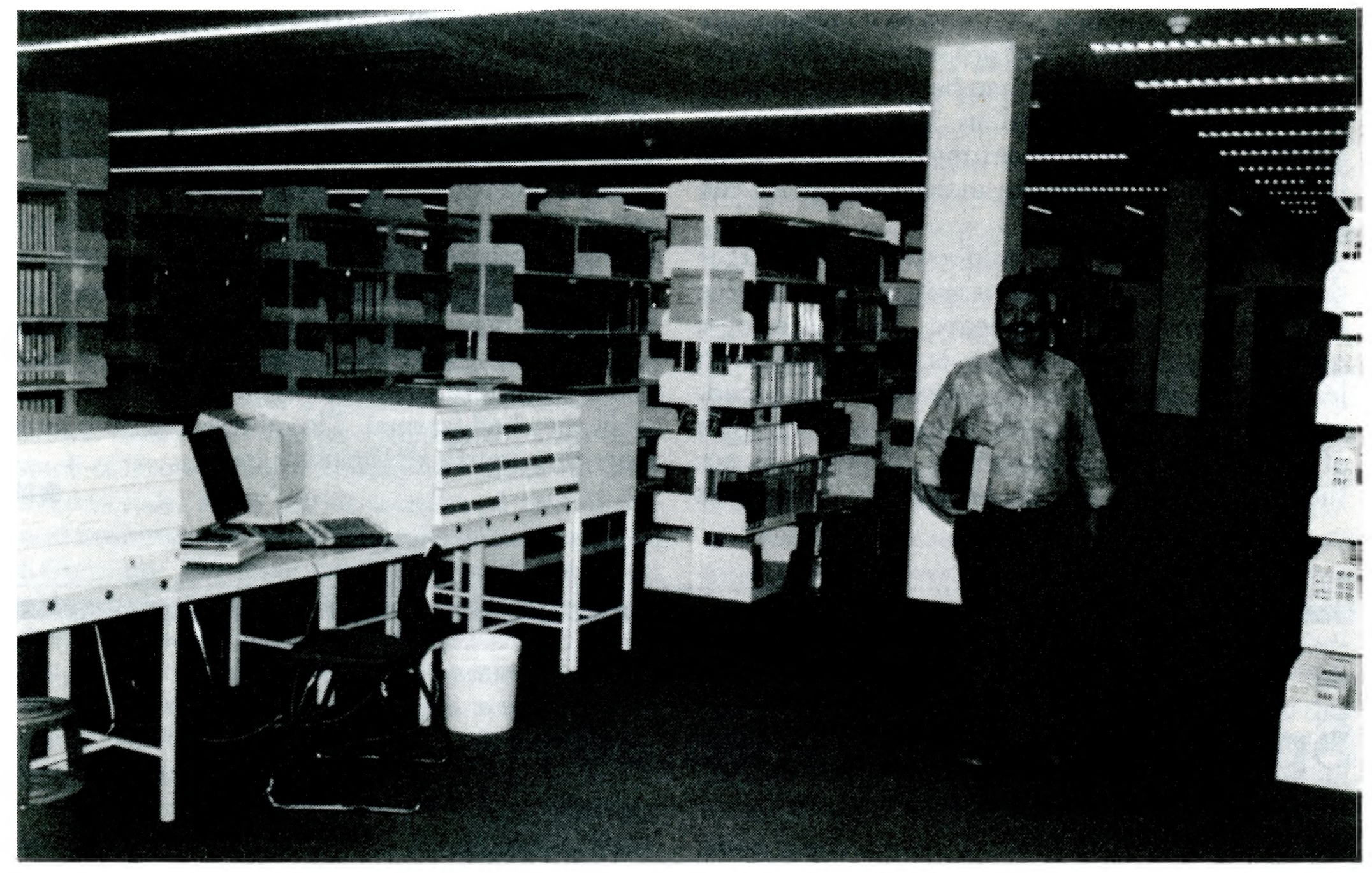

Herr Linzmayer, periodicals assistant at the University of Bamberg's Central Library.

proved dramatically in Germany, I never felt able to express myself freely and easily in German.

Understanding instructions at work was the least taxing of the language challenges. I had a Ger$\mathrm{man} /$ English list of library terms which my exchange partner had given me from her library school curriculum, and it was a great help. Work routines such as filing, checking in serials, or verifying bibliographic information were so similar to those at home that I had little trouble complying with instructions.

Explaining my work routines at Brown to curious German librarians was much more difficult than understanding their routines. Some vocabulary items were not a problem (e.g., Komputer, online), but the concept of RLIN or OCLC was a challenge to communicate. After struggling with my explanantions, it was a joy to compose English replies to letters received in Bamberg from American exchange partners and serial subscription agents. This was the one area in which I felt I had something valuable to offer in return for all the time my German colleagues spent teaching me.

When staff members spoke only to me, they were careful to use High German, i.e., standard vocabulary and pronunciation. When with a group, it was much more difficult to understand as people lapsed into quick-step dialect. Everyone tried to include me in coffee breaks at work and informal evenings in local restaurants, but I usually felt rather isolated. Departments tended not to interact with each other as much as we do at Brown, and I missed having casual conversations with ac- quaintances from many areas of the library.

Outside of the Bamberg library the language barrier continued to be a problem for me. The American bombing of Libya and the accident at the nuclear power plant at Chernobyl both occurred during my tenure in Bamberg. I watched the television news and read the local paper avidly during those times. It was very frightening to understand most of the newscast, yet to feel helpless and uninformed nonetheless. We were told not to eat fresh fruits and vegetables, swim outdoors, or drink fresh milk during the fallout period. My colleagues at work were equally confused about the level of danger, and for days coffee breaks were filled with conversations about half-lifes, millirems, and cancer. My German vocabulary increased by leaps and bounds. I was thankful that neither chocolate nor bread, both specialties of the area, was on the list of contaminated foods!

I discovered differences in the profession which were as challenging as the language barrier. The university system in Germany is entirely statesupported, and all employees are civil servants. A strict hierarchy is observed among the staff and communication trickles slowly in one directiondownward. Supervisors have little say in hiring or firing their staff, and training is haphazard. Everyone from the director to the stack attendants must punch forty hours per week on a time clock. Pay is based on age, rank and number of dependents, with little regard for performance. There are three distinct levels of professional staff: all higher administrators have Ph.D.s; middle-level staff have 
three years of professional training after the equivalent of high school; technical assistants have roughly the equivalent of an associate degree in library science. The level of education achieved determines the civil service rank, and it is impossible to become a higher level administrator without a $\mathrm{Ph} . \mathrm{D}$. Education is venerated, and above a certain level all staff must be addressed "Herr Doktor" or "Frau Doktor."

As I visited the various departments in the Bamberg university libraries, I often felt transported back to the pre-automation days which were the rule in the U.S. years ago. The large acquisitions budget ( 5.5 million Deutschmarks or about $\$ 2.5$ million), which currently comes out of the national budget as well as the Bavarian coffers to support retrospective collection, is administered manually. I could hardly believe my eyes when the head of acquisitions showed me his account ledger, very Prussian-looking and full of painstakingly written figures in black ink.

The cataloging is done in batch mode on floppy disks, then shipped to Munich for compilation into a union catalog on microfiche for most Bavarian university libraries. The fiche catalog is issued every six months. The staff in Bamberg considers our card catalog to be hopelessly old-fashioned, and when I tried to explain that we used a sophisticated bibliographic utility to produce those cards, they just rolled their eyes.

Catalogers prepare only the descriptive portion of the bibliographic record using a MARC-like tagging system which has yet to be standardized nationally. Subject bibliographers provide the subject headings and classification. Subject authority control seemed lax, and having several staff members catalog each book was time consuming and cumbersome. There were no nonprofessional staff doing cataloging, a big contrast with the situation at Brown.

Interlibrary loan is quite heavily used in Bamberg. The staff was always ready and willing to try to get materials elsewhere. They seemed very committed to the concept of resource sharing, and felt that American research libraries were perhaps a bit supercilious in their quest to provide a high percentage of needed materials from their own collections. Approximately 50,000 incoming and outgoing requests are handled annually at the Staatsbibliothek (regional library), which is also a part of the university library system. The Staatsbibliothek is housed in a wing of the baroque "neue Residenz" palace, and to me the most intriguing feature was compact shelving installed in a former wine cellar!

The other university library buildings have charms of their own. The theology reading room has shelves up to the ceiling on all sides, with a spiral staircase up to a balcony. The language and literature branch is a skillfully renovated former gymnasium. The new central library is modern and functional, but sadly lacking in style and warmth. In all branches most of the collection is in closed stacks, but paging seemed remarkably efficient. Many library areas are off limits to users, and in the main library staff members cannot move around the building without keys in hand. My exchange partner was struck by the accessibility of most library rooms and offices at Brown, and I was equally struck by the lack of openness in Bamberg.

I consider myself very fortunate indeed to have had the opportunity to live and work in a foreign country. Successfully coping with the challenge was personally satisfying, but it is difficult to pin down specific professional gains from the exchange experience. I would advise any colleagues who are contemplating participation in such a program to try to arrange for a direct exchange of similar positions. Being an observer for several months is exhausting for the guest, and sheperding a foreigner through many different departments is equally taxing for the host library. A quick overview of the whole library system in Bamberg, with intensive cataloging as my primary activity, would have been much more beneficial to me professionally.

I would further advise potential exchange participants to foreign countries to make sure they feel confident speaking the language of the country they are visiting. Sharing of information will be greatly enhanced if conversations flow easily. In most cases foreign libraries are less technologically advanced than those in the U.S., and foreign exchange partners are bound to be anxious to hear about our automation accomplishments. I feel that exchange librarians have a unique opportunity to foster international cooperation and good will, and to stress that while our procedures may be different, we are all providing similar support to the college or university curriculum.

\section{Handling books safely: A videotape}

Sherlock Holmes and Dr. Watson tackle Research Library Enemy Number One-rough treatment-in a 15-minute educational videotape, "Murder in the Stacks," produced by Columbia University's Preservation Department. The "murder," or ruining of library materials through mishandling, is explained by Holmes to Watson and teaches library staff and users the skills of preventive preservation.

Funded by a grant from the New York State Education Department and performed by professional actors, the videotape has been distributed to research libraries across New York. Additional copies can be purchased for $\$ 35$ from the Preservation Department, Columbia University Libraries, 110 Butler Library, New York, NY 10027; (212) 280-2223. 

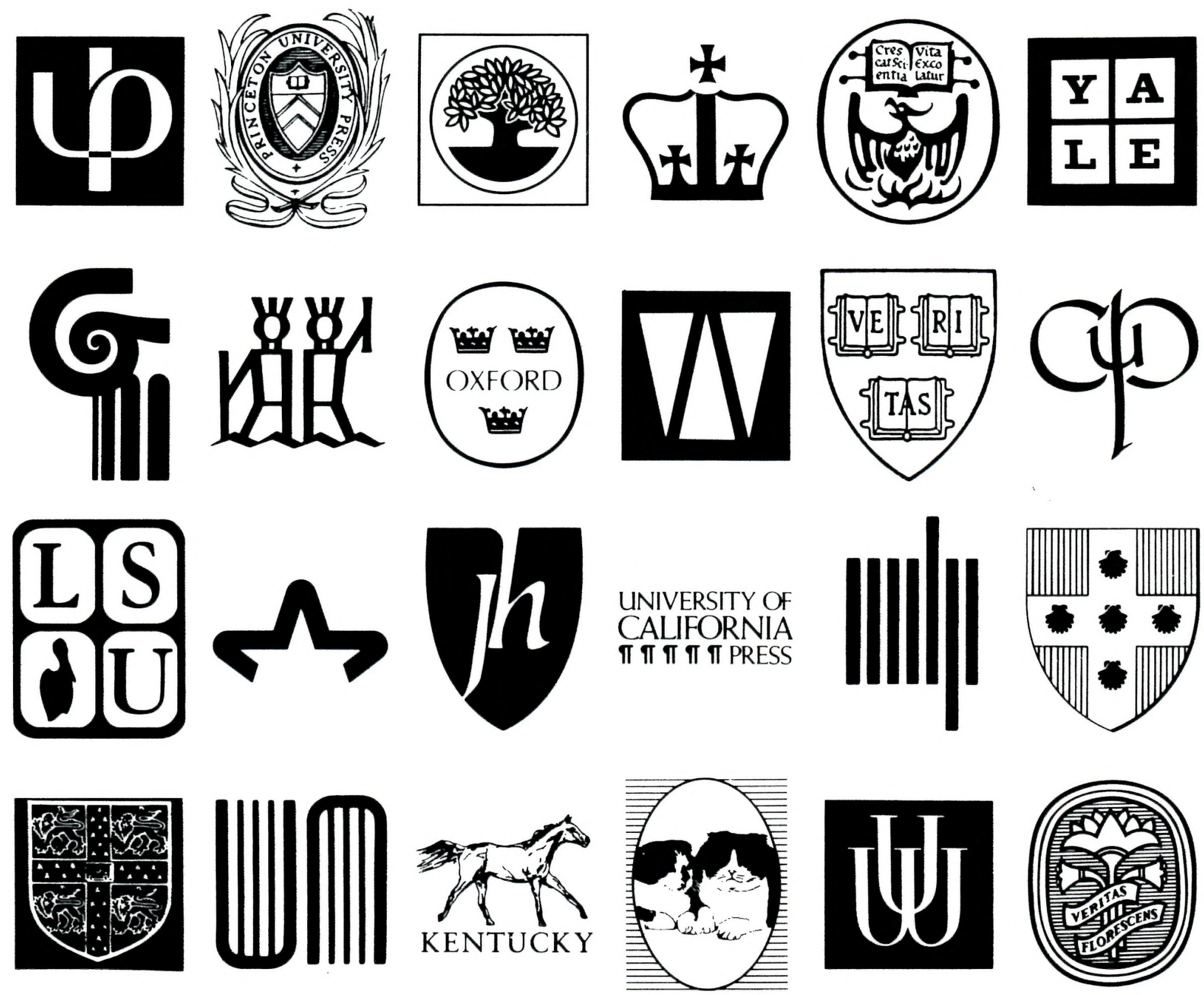

\section{Baker \& Taylor: Summa Cum Laude with 196 University Presses.}

Traditionally, Baker \& Taylor has won highest honors for covering the publishing output of 196 University Presses.

This tradition is upheld by the expertise of our staff academic librarians and our outstanding service. Our academic library customers rely on us to fulfill orders accurately and immediately from our on-hand inventory. We also search for and supply those hard-to-locate titles not immediately available.

Our Approval Program carries the best reputation in the academic library community. And, Baker \& Taylor's DIRECTIONS, a monthly announcement journal of scholarly works, is considered to be the most comprehensive publication of its type.

Shouldn't you join the growing number of academic institutions that look to Baker \& Taylor for professional service and support?

For complete information on how we can assist your collection development professionals, contact the Baker \& Taylor division nearest you. For academic books and services, Baker $\&$ Taylor is at the head of the class.

\section{BAKER \& TAYLOR}

EASTERN DIVISION, 50 Kirby Avenue. Somerville. NJ 08876, Customer Service toll-free: 800-526-3811, 800-352-4841 (In NJ), 800-524-2486 (In Canada) MIDWESTERN DIVISION, 501 South Gladiolus Street, Momence, IL 60954, Customer Service toll-free: 800-435-1845, 800-892-1879 (In IL), 800-358-9148 (In Canada) SOUTHERN DIVISION, Mt. Olive Road, Commerce. Ga 30599. Customer Service toll-free: 800-241-6000, 800-282-6850 (In GA) WESTERN DIVISION, 380 Edison Way, Reno, NV 89564, Customer Service toll-free: 800-648-3944, (702) 786-6700 (In NV, call collect) In Canada, call: (702) 786-6700 


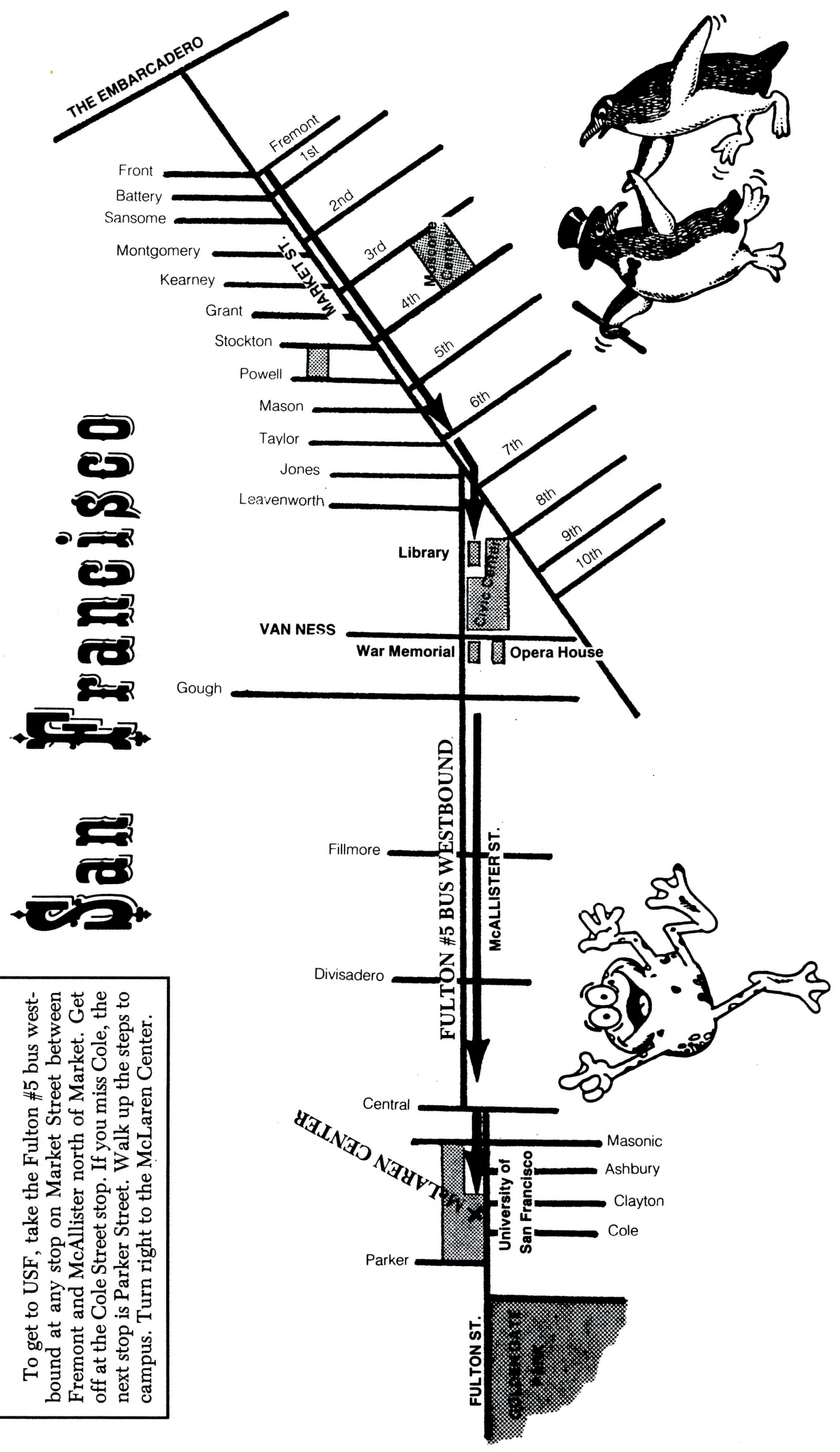

